\title{
APSIL FLAVITHORAX, NEW SPECIES FROM CHILE (DIPTERA, MUSCIDAE)
}

\author{
Márcia S. Couri ${ }^{1,2}$
}

\begin{abstract}
Apsil Malloch, 1929 comprises 10 species endemic to Patagonia and southern Chile. A new species, Apsil flavithorax from Chile is described and illustrated, from three females.

KEYWORDS. Diptera, Muscidae, Apsil, Taxonomy, Neotropical.

\section{INTRODUCTION}

Apsil Malloch, 1929 is a very interesting muscid genus endemic to southern Argentina and Chile. Recent papers contributed to the knowledge of the genus and of its 10 known species (Couri \& Pont, 1999, 2000; Couri, 2000, 2002; Couri \& CARvalho, 2002; CARVAlHo \& Couri, 2002).

The new species here described, based on females, was found in a material loaned from the Canadian National Collection, CNC (Ottawa, Canada). The holotype and one paratype are deposited at $\mathrm{CNC}$ and one paratype at the Museu Nacional, Universidade Federal do Rio de Janeiro, Rio de Janeiro (MNRJ).
\end{abstract}

\section{Apsil flavithorax sp. nov.}

(Figs. 1-5)

Holotype. Female, from Chile, Cautin, Los Coigues, L. Villarica, 16-25.I.1965, Pena col. (CNC). Paratypes: Chile, Dalcahue, Isla Chiloe, Chiloe, 17-31.I.1962, Pena col., 2 females (CNC, MNRJ).

Diagnosis. Thorax yellow contrasting with the brown abdomen, tergite 1 yellow on basal longitudinal half, both dorsally and laterally; lunule yellow; 4 long pairs of frontal bristles, the upper one backwards directed; gena high (fig. 1), acrostichal cilia biseriated.

Coloration: frons yellowish brown, yellow at lunule; parafrontal, face, parafacial and gena faint golden pollinose. Vertex and ocellar triangle dark brown. Antenna and arista brown. Palpus yellow. Mesonotum yellow with very faint yellowish brown marks, difficult to observe; pleurae yellow; calypter white, halter yellow. Wing hyaline, with no spots. Femora brown, a little yellow at base and apex (holotype with anterior surface of

1. Museu Nacional, Universidade Federal do Rio de Janeiro, Quinta da Boa Vista, São Cristóvão, 20940-040, Rio de Janeiro, RJ, Brasil.

2. Researcher CNPq. 


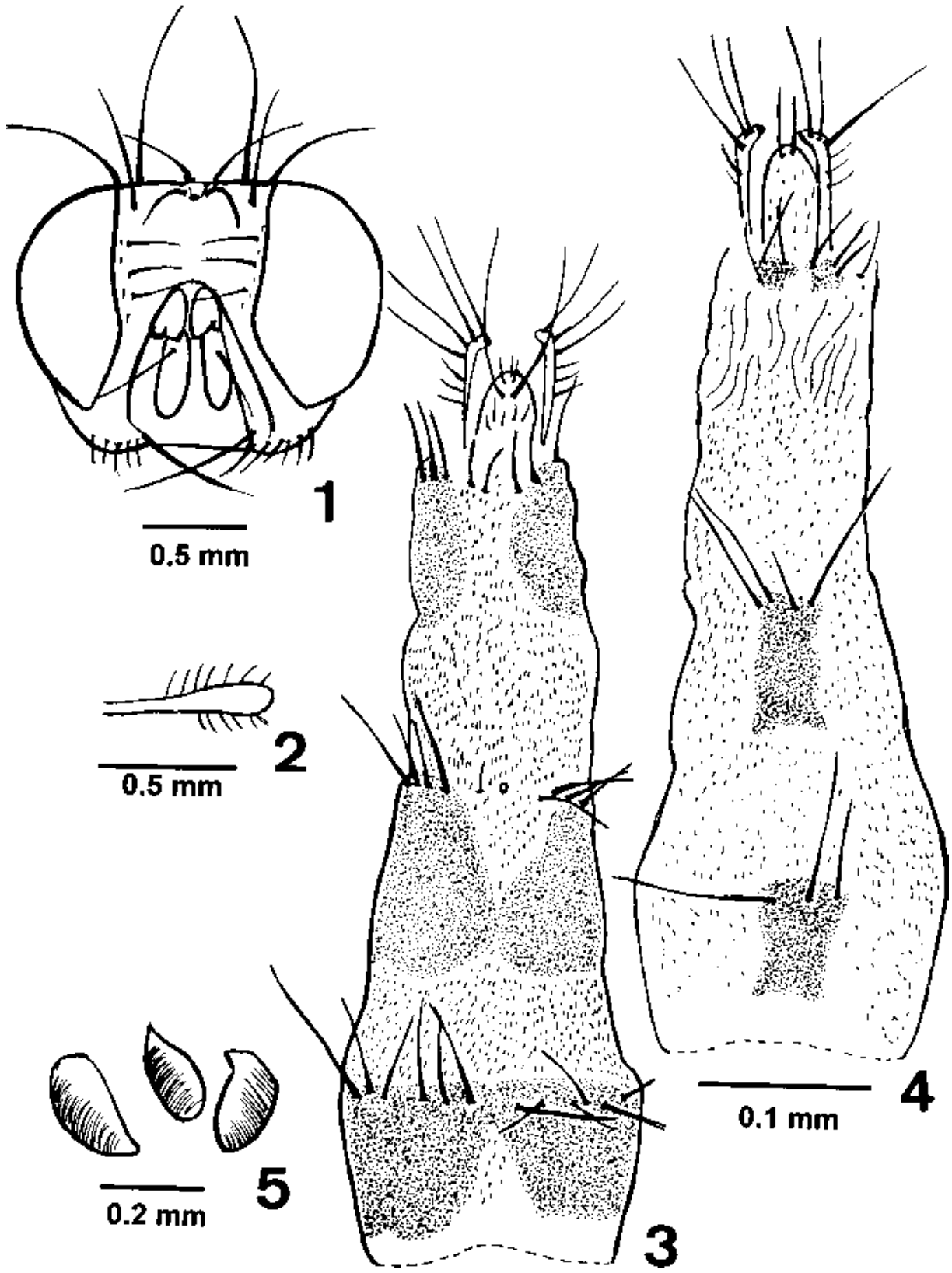

Figs. 1-5. Apsil flavithorax sp. nov, female (holotype dissected): 1, head, frontal view; 2, palpus; 3, terminalia, dorsal; 4 , ventral; 5 , spermathecae. 
hind femur yellow on basal half); tibia and tarsi yellowish brown. Abdomen with very faint paired marks, difficult to observe.

Females length: 5.0-6.0 mm; wing: 5.5-6.5 mm.

Head: frons with 4 long pairs of frontal bristles; flagellomere about twice as long as pedicel; gena high (fig. 1); palpus dilated at apex (fig. 2). Proboscis with developed teeth.

Thorax: acrostichal hairs in two series; first pair of pre-sutural dorsocentral bristles about half size of the second one, the first two post-sutural the same size of the second pre-sutural, and the last the longest. Katepisternal bristles long, the posterior longer. Both calypters round, the lower one about 1.5 the length of the upper one. Fore femur with a row of bristles on posterodorsal and posteroventral surfaces. Fore tibia with a median bristle on posterior surface, dorsal pre-apical bristle; posterodorsal and anterodorsal with long and fine pre-apical bristles. Mid femur with a series of bristles on basal half of anterior surface; ventral surface with a row of sparse bristles at basal two thirds. Mid tibia with a median bristle on anterior and posterior surfaces, a pre-apical bristle on dorsal and posterodorsal surfaces and an apical bristle on anteroventral, anterior and posteroventral surfaces. Hind femur with a complete row of strong bristles on anterodorsal and anteroventral surfaces. Hind tibia with a long median bristle on anterodorsal surface, 2 bristles on apical third of posterodorsal surface; a long pre-apical bristle on dorsal surface and one sub-median bristle on anteroventral surface. bristles.

Abdomen: all tergites with a marginal row of bristles; tergite 5 with a row of discal

Terminalia: cerci long; microtrichia in all segments (figs. 3, 4). Spermathecae pearshaped (fig. 5).

Comments. No male in the series. Although the series has only females, Apsilflavithorax is easily distinguished from the other congeners, by the conspicuous yellowish color of the mesonotum. In the key of Couri \& CARvalHo (2002), A. flavithorax approaches A. atripes Malloch, 1934 (couplet 12, female) but no dark brown central vitta is present on mesonotum. Distribution. Chile.

Acknowledgments. To Dr. Jeffrey Cumming (CNC) for the opportunity to study the material.

\section{REFERENCES}

Carvalho, C. J. B. \& Couri, M. S. 2002. Cladistic and biogeographic analysis of Apsil Malloch and Reynoldsia Malloch (Diptera, Muscidae, Coenosiinae, Coenosiini). Proc. ent. Soc. Wash., Washington, 104(2):309-317.

Couri, M. S. 2000. Revision of Apsil Malloch (Diptera, Muscidae, Coenosiinae, Coenosiini). Studia dipterologica, Halle (Salle), 7(1):45-57.

2002. A new species of Apsil Malloch (Diptera, Muscidae). Revta bras. Zool., Curitiba, 19(1):105-108.

Couri, M. S. \& Carvalho, C. J. B. 2002. Part II. Apical Groups. In: Carvalho, C. J. B. ed. Muscidae (Diptera) of the Neotropical Region: Taxonomy. Curitiba, Universidade Federal do Paraná. p.133-257.

Couri, M. S. \& Pont, A. C. 1999. Key to the world Coenosiini (Diptera, Muscidae, Coenosiinae). Studia dipterologica, Halle (Salle), 6(1):93-102.

2000. Cladistic analysis on Coenosiini (Diptera, Muscidae, Coenosiinae). Syst. Ent., London, 25:373-392.

Recebido em 25.06.2002; aceito em 06.11.2002. 